\title{
EVALUASI PELAPORAN SPT TAHUNAN WAJIB PAJAK ORANG PRIBADI SECARA ONLINE MELALUI E-FILING PADA KPP PRATAMA SINGARAJA TAHUN 2015-2016
}

\author{
Komang Ayu Widiantari \\ Jurusan Akuntansi Program Diploma III, \\ Universitas Pendidikan Ganesha,Singaraja \\ Email : wdiantari ayu15@gmail.com
}

\begin{abstract}
Abstrak
Penelitian ini bertujuan untuk mengetahui Bagaimana Prosedur Pelaporan SPT Tahunan Wajib Pajak Orang Pribadi Karyawan melalui e-filing pada KPP Pratama Singaraja, Tingkat kepatuhan penyampaian SPT Tahunan Wajib Pajak Orang Pribadi Karyawan pada tahun 2015-2016 apabila dikaitkan dengan e-filing, Kendala yang dihadapi pihak KPP Pratama Singaraja dalam proses pelaksanaan $e$-filing, serta Langkah yang diupayakan oleh KPP Pratama Singaraja untuk mengurangi kendala dalam proses pelaksanaan e-filing.

Obyek penelitian adalah Pelaporan SPT Tahunan Wajib Pajak Orang Pribadi secara online melalui e-filing, sedangkan Subyek penelitian ini adalah KPP Pratama Singaraja. Pada penelitian ini metode pengumpulan data yang digunakan oleh penulis adalah wawancara dan dokumentasi. Analisis data yang digunakan adalah analisis deskriptif kualitatif.

Hasil Penelitian menyatakan bahwa Prosedur Pelaporan SPT Tahunan Wajib Pajak Orang Pribadi Karyawan dengan e-filing pada KPP Pratama Singaraja tahun 2015-2016 sudah sesuai dengan Prosedur Pelaporan SPT Tahunan Wajib Pajak Orang Pribadi Karyawan dengan e-filing yang ditetapkan oleh Direktorat Jenderal Pajak,
\end{abstract}

Kata Kunci : SPT Tahunan, e-filing, Pajak

\begin{abstract}
This study aims to find out how the Reporting Procedure of SPT Annual Personal Taxpayer Employee through e-filing on KPP Pratama Singaraja, Compliance rate of submission of Annual Taxpayer Employee Personal Taxes in 2015-2016 when associated with e-filing,

Constraints faced by the KPP Pratama Singaraja in the process of e -filing, and Steps pursued by KPP Pratama Singaraja to reduce the obstacles in the process of e-filing execution.

The object of this research is Reporting SPT Annual Personal Taxpayers online through efiling, while the subject of this research is KPP Pratama Singaraja. In this study, data collection methods used by the authors are interviews and documentation. Data analysis used is qualitative descriptive analysis

Research states that the SPT Annual Reporting Procedures Individual Taxpayer employees with e-filing on STO Singaraja years 2015-2016 are in accordance with the Annual Tax Return Reporting Procedures Individual Taxpayer employees with e-filing set by the Directorate General of Tax, Compliance Level Individual taxpayer employees when linked with e-filing in 2015-2016 increased and have reached the targets set nationally.
\end{abstract}

Keywords : Annual SPT, e-filing, Tax

\section{Pendahuluan}

Perkembangan era globalisasi sekarang ini ditandai oleh berbagai macam perubahan dalam berbagai aspek kehidupan manusia, khususnya bidang teknologi. Salah satu akibat positif dari kemajuan bidang teknologi adalah dimungkinkannya pengiriman dan penyampaian informasi dapat dilakukan dengan lebih cepat. Mengantisipasi perkembangan informasi dan teknologi tersebut, Direktorat Jenderal Pajak berusaha untuk memenuhi aspirasi Wajib Pajak dengan mempermudah tata cara pelaporan SPT baik itu SPT Masa maupun SPT Tahunan yaitu dengan e-filing. E-filing adalah sarana pelaporan pajak secara 
online dan realtime menggunakan media internet dengan melalui penyedia layanan aplikasi atau Application Service Provider (Wiyono, 2008). Berdasarkan data yang diperoleh pada Kantor Pelayanan Pajak Pratama Singaraja untuk tahun 2015 Wajib Pajak Orang Pribadi Karyawan yang terdaftar sebanyak 36.040 sedangkan untuk realisasi SPT Tahunan Wajib Pajak Orang Pribadi Karyawan pada tahun 2015 sebanyak 25.957, dan untuk tahun 2016 Wajib Pajak Orang Pribadi Karyawan yang terdaftar sebanyak 40.197 sedangkan untuk realisasi SPT Tahunan Wajib Pajak Orang Pribadi Karyawan pada tahun 2016 sebanyak 29.783.

Dari pernyataan di atas bisa di buat rumusan masalah sebagai berikut

1. Bagaimana Prosedur Pelaporan SPT Tahunan Wajib Pajak Orang Pribadi Karyawan melalui $e$-filing pada KPP Pratama Singaraja?

2. Bagaimana tingkat kepatuhan penyampaian SPT Tahunan Wajib Pajak Orang Pribadi Karyawan pada tahun 2015-2016 apabila dikaitkan dengan e-filing?

3. Apa yang menjadi kendala bagi pihak KPP Pratama Singaraja dalam proses pelaksanaan $e$-filing?

4. Langkah apa yang diupayakan oleh KPP Pratama Singaraja untuk mengurangi kendala dalam proses pelaksanaan e-filing? ini yaitu :

Berdasarkan Rumusan Masalah Penelitian, Adapun Tujuan dari Hasil Penelitian

1. Dapat mengetahui Prosedur Pelaporan SPT Tahunan Wajib Pajak Orang Pribadi Karyawan melalui e-filing pada KPP Pratama Singaraja.

2. Dapat mengetahui tingkat kepatuhan penyampaian SPT Tahunan Wajib Pajak Orang Pribadi Karyawan pada tahun 2015-2016 apabila dikaitkan dengan e-filing.

3. Dapat mengetahui kendala yang dihadapi pihak KPP Pratama Singaraja dalam proses pelaksanaan $e-$ filing.

4. Dapat mengetahui langkah yang diupayakan oleh KPP Pratama Singaraja untuk mengurangi kendala dalam proses pelaksanaan e-filing.

\section{METODE PENELITIAN}

Penelitian yang dilakukan ini merupakan penelitian deskriptif kualitatif, dimana di dalam penelitian ini menyajikan gambaran yang benar-benar terjadi di lapangan. Penelitian ini bertujuan untuk mengevaluasi pelaksanaan system e-filing dalam pelaporan SPT Tahunan Wajib Pajak Orang Pribadi pada KPP Pratama Singaraja.
a. Lokasi Penelitian : KPP Pratama Singaraja
b. Objek Penelitian :
Evaluasi Pelaporan SPT Tahunan Wajib Pajak Orang Pribadi secara online dengan e-filing
c. Subjek Penelitian
KPP Pratama Singaraja
d. Jenis Data
Data Kualitatif
e. Sumber Data
Data Primer dan Data Sekunder
f. Teknik Pengumpulan Data
Wawancara dan Dokumentasi
g. Teknik Analisis Data :
Teknik Analisis Deskriptif Kualitatif

\section{HASIL DAN PEMBAHASAN}


1. Secara umum Prosedur Pelaporan SPT Tahunan Wajib Pajak Orang Pribadi Karyawan melalui e-filing pada KPP Pratama Singaraja sebagai berikut, (a) Mengajukan permohonan e-FIN ke Kantor Pelayanan Pajak terdekat, (b) Mendaftarkan diri sebagai Wajib Pajak e-filing di situs https://djponline.pajak.go.id. (c) Menyampaikan SPT Tahunan PPh Wajib Pajak Orang Pribadi menggunakan fasilitas e-filing melalui situs https://djponline.pajak.go.id.

(d) Bagi pembayar pajak yang baru pertama kali menggunakan e-filing, langkah awal yang harus dilakukan adalah mengajukan permohonan aktivasi E-FIN ke Kantor Pelayanan Pajak (KPP) atau Kantor Pelayanan Penyuluhan dan Konsultasi Perpajakan (KP2KP). (e) Setelah memperoleh E-FIN, langkah selanjutnya adalah mendaftarkan diri dengan membuat akun pada layanan pajak online. (f) Langkah terakhir adalah mengisi dan mengirim SPT tahunan.

2. Tingkat Kepatuhan Wajib Pajak Orang Pribadi Karyawan dalam melaporkan SPT Tahunan dari tahun 2015 sampai 2016 meningkat. Hal ini ditunjukkan dari Rasio Kepatuhan Wajib Pajak Orang Pribadi Karyawan pada tahun 2015 sebesar $72,02 \%$, sedangkan untuk tahun 2016 sebesar 74,12\% , dari jumlah Wajib Pajak yang efektif pada tahun tersebut. Serta penyampaian SPT Tahunan di KPP Pratama Singaraja Tahun 2015-2016 telah memenuhi Target Rasio Kepatuhan Penyampaian SPT Tahunan Wajib Pajak yang ditetapkan secara Nasional yaitu , Untuk Tahun 2015 Target Rasio Kepatuhan Penyampaian SPT Tahunan yang ditetapkan secara Nasional sebesar $70 \%$ sedangkan pada KPP Pratama telah mencapai 72,02\%. Untuk tahun 2016 Target Rasio Penyampaian SPT Tahunan yang ditetapkan secara Nasional sebesar $72,5 \%$, sedangkan pada KPP Pratama Singaraja mencapai sebesar $74,1 \%$.

3. Kendala bagi pihak KPP Pratama Singaraja dalam proses pelaksanaan e-filing Dalam pelaksanaan Pelaporan SPT Wajib Pajak Orang Pribadi Karyawan melalui e-filing tahun 2015-2016, KPP Pratama Singaraja mengalami beberapa kendala sebagai berikut, (a) Kendala pada system DJP, Pelaksanaan pelaporan SPT Tahunan yang biasanya dilakukan pada Bulan Februari-April dengan menggunakan system DJP online yang terkadang error dan sulit untuk diakses karena banyaknya orang yang mengakses web tersebut secara bersamaan sehingga memperlambat proses pengisian data SPT Tahunan.

(b) Ketidakstabilan jaringan internet, Dengan menggunakan WIFI yang tersedia pada KPP Pratama Singaraja, Jaringan Internet yang tersedia untuk mengakses internet cenderung lambat karena banyak Wajib Pajak maupun Pegawai yang menggunakannya secara bersamaan. (c) Sarana dan Petugas Pelayanan yang kurang memadai, Jumlah komputer yang tersedia serta petugas pelayanan masih kurang memadai, karena pada saat pelaporan SPT Tahunan, Pihak KPP Pratama Singarajahanya terdapat 12 Loket sedangkan antrian kurang lebih mencapai 300 Wajib Pajak per hari bahkan saat mendekati batas akhir pelaporan bisa mencapai sekitar 500 Wajib Pajak. (d) Faktor Usia Wajib Pajak, Faktor usia menjadi salah satu kendala bagi Wajib Pajak dalam pelaporan SPT Tahunan melalui e-filing karna biasanya sejak dahulu Wajib Pajak terbiasa melakukan pelaporan secara manual, terlebih pada Wajib Pajak yang telah pensiun.

4. Langkah yang diupayakan oleh KPP Pratama Singaraja untuk mengurangi kendala dalam proses pelaksanaan e-filing, Dalam mengurangi kendala yang dihadapi KPP Pratama Singaraja dalam Pelaksanaan Pelaporan SPT Tahunan Wajib Pajak Orang Pribadi Karyawan pada tahun 2015-2016, dilakukan berbagai upaya sebagai berikut, (a) Memperbanyak Loket untuk Proses Pelaporan SPT Tahunan agar antrian tidak terlalu padat, (b) Memperbaiki Jaringan Internet dan mengkhususkan Jaringan tersebut hanya untuk pelayanan e-filing, (c) Menyediakan Layanan Mandiri e-filing, bagi Wajib Pajak yang ingin belajar tata cara menggunakan e-filing. (d) Memperpanjang batas akhir pelaporan, diperpanjang sampai dengan 21 April. (e) Menerima pelayanan khusus untuk e-filing pada hari Senin-Minggu mulai dari pukul 08.00 WITA sampai dengan 16.00 WITA hanya pada pertengahan bulan Maret hingga batas akhir Pelaporan SPT Tahunan. (f) Melakukan sosialisasi untuk Wajib Pajak tentang e-filing yang diharapkan Wajib Pajak 
dapat memanfaatkan fasilitas e-filing ini secara benar. (g) Menyediakan fasilitas pembuatan e-mail dan pengecekkan e-fin agar proses pelaporan menjadi lebih cepat, bagi Wajib Pajak yang lupa e-mail ataupun e-fin.

\section{Kesimpulan dan Saran}

1. Prosedur Pelaporan SPT Tahunan Wajib Pajak Orang Pribadi Karyawan dengan e-filing pada KPP Pratama Singaraja tahun 2015-2016 sudah sesuai dengan Prosedur Pelaporan SPT Tahunan Wajib Pajak Orang Pribadi Karyawan dengan e-filing yang ditetapkan oleh Direktorat Jenderal Pajak.

2. Tingkat Kepatuhan Wajib Pajak Orang Pribadi Karyawan apabila dikaitkan dengan e-filing pada tahun 2015-2016 meningkat dan telah mencapai target yang telah ditetapkan secara Nasional, yaitu dilihat dari Rasio Kepatuhan WPOP Karyawan tahun 2015 sebesar $72,02 \%$ sedangkan Rasio Kepatuhan WPOP Karyawan tahun 2016 sebesar 74,1\%.

3. Dari pelaksanaan pelaporan SPT Tahunan dengan e-filing pada KPP Pratama Singaraja terdapat beberapa kendala yaitu, (a) Kendala pada system DJP, (b) Ketidakstabilan Jaringan Internet, (c) Sarana dan Petugas Pelayanan yang kurang memadai, (d) Faktor Usia Wajib Pajak.

4. Langkah yang diupayakan oleh KPP Pratama Singaraja untuk mengurangi kendala dalam proses pelaksanaan e-filing yaitu, (a) Menambah Loket untuk Pelayanan e-filing, (b) Memperbaiki Jaringan Internet, (c) Menyediakan Layanan Mandiri e-filing, (d) Memperpanjang batas akhir Pelaporan SPT Tahunan, (e) Menerima Pelayanan khusus efiling dari hari Senin-Minggu, (f) Melakukan Sosialisasi tentang e-filing untuk Wajib Pajak, (g) Menyediakan layanan pembuatan e-mail dan pencetakan e-fin.

Berdasarkan simpulan, maka penulis menyarankan beberapa Upaya yang dapat dilakukan untuk mengurangi kendala terkait Pelaksanaan Pelaporan SPT Tahunan melalui e-filing untuk meningkatkan Kinerja Kantor Pelayanan Pajak Pratama Singaraja :

1. Meningkatkan Intensitas sosialisasi tentang e-filing, hal ini dapat berupa pemasangan Spanduk yang dapat dipasang ditempat-tempat strategis atau mengadakan sosialisasi di Tempat Umum seperti di Taman Kota Singaraja. Serta akan lebih baik lagi apabila ketika mengadakan sosialisasi, KPP Pratama Singaraja memberikan doorprice kepada beberapa Wajib Pajak yang dimaksudkan supaya Wajib Pajak memiliki antusiasme yang lebih untuk menghadiri dan memperhatikan sosialisasi yang diadakan oleh KPP Pratama Singaraja.

2. Menambah jumlah Petugas Pelayanan serta sarana di Tempat Pelayanan Terpadu (TPT) pada bulan Februari hingga April. Karena di bulan-bulan tersebut sudah mulai banyak Wajib Pajak berdatangan untuk melaporkan kewajiban Perpajakan Tahunannya sehingga dapat mengurangi padatnya antrian.

3. Penyampaian SPT Tahunan secara e-Filing yang saat ini hanya melayani pelaporan untuk Formulir SPT Tahunan 1770 S dan 1770 SS diharapkan untuk kedepannya dapat dilakukan untuk pelaporan oleh berbagai jenis Formulir SPT Tahunan, seperti 1770.

\section{DAFTAR PUSTAKA}

Direktorat Jenderal Pajak.2017. "Surat Pemberitahuan". Tersedia pada https://www.onlinepajak.com/id/spt-surat-pemberitahuan (diakses tanggal 27 Maret 2017)

Direktorat Jenderal Pajak. 2017. "Seri PPh Objek Pajak Penghasilan". Tersedia pada http://www.pajak.go.id/content/seri-pph-objek-pajak-penghasilan (diakses tanggal 27 Maret 2017)

Harris Nugraha. 2016. Backup Buku Profil KPP Pratama Singaraja.Singaraja : Magdalena 
Kemenkeu. 2017. "Penyampaian Surat Pemberitahuan Online e-filing". Tersedia pada http://www.kemenkeu.go.id/Page/penyampaian-surat-pemberitahuan online-efiling (diakses tanggal 28 Maret 2017)

Kring Pajak. 2017. "Fungsi Pajak bagi suatu Negara". Tersedia pada http://kringpajak.com/fungsi-pajak-bagi-suatu-negara/ (diakses tanggal 28 Maret 2017)

Kring Pajak. 2017. "Objek Pajak Penghasilan". Tersedia pada http://kringpajak.com/objekpajak-penghasilan/ (diakses tanggal 28 Maret 2017)

Kring Pajak. 2017. "Pengertian Pajak Penghasilan". Tersedia pada http://kringpajak.com/pengertian-pajak-penghasilan/ (diakses tanggal 28 Maret 2017)

Mulyono Djoko. Buku Pengantar Hukum Pajak Edisi Revisi. Jakarta : Salemba Empat

SH Mardiasmo. 2011. Buku Edisi Revisi Perpajakan Terbaru. Yogyakarta : Ekonisia 